\title{
O TRABALHO DOCENTE: ELEMENTOS PARA UMA TEORIA DA DOCÊNCIA COMO PROFISSÃO DE INTERAÇÕES HUMANAS
}

Resenhado por: Camila Lopes Cravo Matos ${ }^{1}$

TARDIF, M.; LESSARD, C. O trabalho docente: elementos para uma teoria da docência como profissão de interações humanas. Petrópolis: Editora Vozes, 9. Ed., 2014.

Claude Lessard e Maurice Tardif são professores da Universidade de Montreal, Canadá, onde participam do mais importante centro de pesquisa canadense sobre a formação e profissão docente - Centro de Pesquisa Interuniversitária sobre a Formação e a Profissão Docente (CRIFPE). Nos últimos anos temos tido acesso em língua portuguesa a diferentes obras e artigos desses autores sobre trabalho e saberes docentes.

O livro O trabalho docente: Elementos para uma teoria da docência como profissão de interações humanas busca verificar o cerne do processo de escolarização analisando o trabalho dos indivíduos que efetivam essa atividade: os professores, os alunos e os outros contingentes humanos da ambiência escolar. Os autores buscam abrir campo para uma pesquisa acerca do trabalho docente situada entre as mais variadas disciplinas e teorias relacionadas entre si e o saber, influenciam-se das pesquisas em sociologia do trabalho e das organizações, ciências da educação, ergonomia, teorias da ação e ciências cognitivas.

Constroem seus argumentos dentro de uma perspectiva pautada nos avanços da pesquisa empírica, na intenção explícita de uma coleta de dados que garantiu o desenvolvimento de bases conceituais sólidas para fazer-se um estudo amplo da docência no âmbito escolar. Os autores mobilizam essa base de conhecimentos, ampliam-na e alcançam um grau maduro de profundidade, podendo assim, perfazer críticas a fim de aplicá-las aos estudos da docência.

É a análise do trabalho do professor, em suas mais variadas interações, que constitui objeto da obra analisada, enfatizando alguns assuntos diretivos que norteiam

\footnotetext{
${ }^{1}$ Cursando doutorado em Ciências Humanas - Educação, na área de concentração: Formação de Professores, pela Pontifícia Universidade Católica do Rio de Janeiro. Professora da Universidade do Estado de Minas Gerais. Contato: cravokta@gmail.com
} 
Atos de Pesquisa em Educação - ISSN 1809-0354

Blumenau - vol. 11, n. 2, p.656-660 ago./nov. 2016

DOI: http://dx.doi.org/10.7867/1809-0354.2016v11n2p656-660

todo o processo escolar, aludindo sobre: como o fato de o professor trabalhar com seres humanos repercute sobre ele próprio, seus conhecimentos, identidade, suas experiências profissionais, os dispositivos da organização do trabalho e suas interferências. Descrevem, analisam e compreendem o trabalho docente tal como é desenvolvido, conforme as representações de situações de trabalho experienciado pelos professores, e, para essa tarefa, fundamentam-se em 150 entrevistas feitas junto a professores, complementadas por uma centena de outras entrevistas realizadas com outros promotores da educação escolar.

O livro é dividido em sete capítulos, sendo que o $1^{\circ}$ capítulo inicia-se com a apresentação e discussão do quadro teórico que embasa todo desenvolvimento das análises perpetradas no decorrer do texto. Oferece elementos gerais de análise que podem ser utilizados em diversos contextos escolares, parte de contextos globais como: organização do trabalho escolar, consideração das situações cotidianas de interação entre os atores escolares e professores e alunos em suas atividades, permitindo situar a análise no particular das práticas específicas do trabalho escolar compreendido em um processo mais global de escolarização.

O capítulo 2 enfatiza as relações entre algumas características sociais e organizacionais da escola e as maneiras de realização do trabalho docente, do trabalho escolar e do conjunto de trabalhos efetivados por todos os agentes escolares. Mostra a estrutura da organização da escola configurando as características das operações e dos modos de realização do ensino, evidenciando a estrutura escolar como orientadora de todo o trabalho docente. Os autores dão continuidade às análises sobre a organização do trabalho escolar no capítulo posterior, o $3^{\circ}$, tratando de sua crescente burocratização, dando ênfase também às questões de poder dentro dessas organizações e as ramificações desses processos nos recursos humanos envolvidos nesse imbricado jogo de interesses.

No 4ํㅜ capítulo o enfoque recai para a figura do professor, suas condições de trabalho, a maneira como são utilizados seus tempos e espaços escolares/extraescolares e os componentes que compõem as tarefas dos professores em as mais diversas atividades a eles atribuídas, essas tarefas temporalizadas são motivo de duras observações. O capítulo $5^{\circ}$ enriquece as análises feitas nos três capítulos anteriores, pois 
Atos de Pesquisa em Educação - ISSN 1809-0354

Blumenau - vol. 11, n. 2, p.656-660 ago./nov. 2016

DOI: http://dx.doi.org/10.7867/1809-0354.2016v11n2p656-660

completa as análises da organização do trabalho escolar, na medida em que contempla aspectos temporais dentro dos quadros organizacionais; isso feito, concebem uma proposta de reflexão onde o trabalho docente não se efetiva senão através desses mesmos quadros organizacionais e temporais, usando a lógica do pertencimento e à atividade orientada por objetivos postos.

O capítulo 6 trata da questão dos objetivos, já um pouco vista no capítulo anterior, analisam-se os objetivos gerais do ensino, da escola e do mandato dos professores, sem excluírem observações sobre os programas escolares, elemento que elegem como sendo parte não negligenciável da identidade profissional do docente, através do sentimento de pertencimento a ele atribuído de variadas formas. Mostram as escolhas dos professores no que se refere aos seus objetivos e as consequências práticas no cotidiano escolar, e é dentro desse percurso que propõem o que denominam "trabalho curricular", onde tentam compreender os movimentos de interpretação, transformação e adaptação, feitos pelos docentes em seu trabalho cotidiano. Passam então em sequência, a abordarem o objeto mesmo do trabalho docente, isto é, o que dizem parecer ser essencialmente formado pelas relações de interação entre alunos e professores.

Ao apresentarem o último $7^{\circ}$ capítulo buscam completar a abordagem oferecida no anterior, na medida em que continuam a mostrar as interações humanas tangenciando os processos escolares e marcando em profundidade todos os outros quesitos do processo de trabalho do professor. Essas interações humanas são consideradas de grande efeito sobre o trabalho do docente, podendo movimentar alterações nos conjuntos das suas relações, em suas práticas e até mesmo em sua identidade profissional. Os autores buscam tratar das expectativas dos professores com relação aos seus alunos e as dinâmicas que envolvem essa relação. Esse capítulo humaniza os entes, leva a baila aspectos das personalidades envolvidas e de seus anseios e desejos, trata de questões subjetivas que se concretizam nas relações e inter-relações diárias e cotidianas. Buscam determinar as características do ensino frente a seu objeto de trabalho 'aluno', com muitas das nuances controversas desse embate diário e não consensual.

Os autores construíram seus argumentos fundamentando-se em uma abordagem sociológica, tratando a docência como atividade de trabalho desenvolvida em organizações em que os professores interagem com outros indivíduos, dizendo-nos que 
Atos de Pesquisa em Educação - ISSN 1809-0354

Blumenau - vol. 11, n. 2, p.656-660 ago./nov. 2016

DOI: http://dx.doi.org/10.7867/1809-0354.2016v11n2p656-660

são possíveis essas trocas decorrentes do lugar que ocupam, dessa forma, pode-se compreender o trabalho dos professores não somente pelos aspectos técnicos, específicos às tarefas a que são chamados, mas também, pelo ângulo das atividades emocionais e interacionais envolvidas, pelas vivências interativas que estão imersos a todo o momento.

São os aspectos humanos tratados dentro de um formato também humanizado, com uma visão panorâmica possibilitada pela empiria, onde fotografaram o "chão da escola" e suas relações, evidenciando as condições, as tensões e os dilemas que fazem parte do trabalho docente, bem como as vivências das pessoas que o realizam diariamente, que tornam a obra diferenciada diante das demais que se ocupam do trabalho docente.

Os autores têm como base central de suas proposições analisarem o trabalho cotidiano dos professores de base, e o fazem, pelo ângulo das exigências que vigoram suas atividades, como também pelas suas experiências cotidianas.

Situaram seus estudos sobre a docência na problemática do trabalho, subtraindo de forma crítica o objeto de estudo da grande influência exercida pelos modelos de análises advindos de outras esferas de trabalho. Para atingirem o intento apresentaram a docência como uma forma de trabalho sobre o humano, um trabalho estabelecido pelas interações, no qual o trabalhador se relaciona com seu objeto de trabalho de forma radical, dessa maneira, superam a percepção normativa do ofício, centrando as análises da docência na organização e no processo de trabalho dos professores. Corroborando comas ideias propostas na obra agora observada, podemos verificar em outro título de Maurice Tardif "Saberes docentes e formação profissional" (2002), uma convergência, no sentido dos saberes e da prática invisível, elástica, do trabalho docente, agora aprimorada de ideias e conceitos, pois já apontava para análises com relação aos saberes docentes em conjunto às realidades materiais que possibilitam o próprio trabalho de fato, realidades sociais, organizacionais e humanas nas quais os professores se encontram mergulhados e que compõem seu trabalho. Pode-se dizer que Tardif e Lessard (2005) aprofundam as questões suscitadas e as colocam imersas nos ambientes de trabalho com ampliação dos fatores sociológicos que os cercam, dessa forma constroem um campo de análises mais completo e rico de detalhes. 
Embora apresente uma realidade 'exterior', muito diversa funcional e estruturalmente da realidade brasileira e também dos países latino-americanos, "O trabalho docente: Elementos para uma teoria da docência como profissão de interações humanas" (2005), muito contribui para as pesquisas no campo da profissão docente, da organização das escolas e seus sistemas educacionais, bem como suscita graves reflexões referentes às relações e interações humanas promovidas pelo ofício de professor e as consequências trazidas para a identidade e a profissão docente, bem como, para a organização nas escolas públicas, seu lócus de atuação.

A presente obra é de fundamental importância para os estudantes universitários dos cursos de formação de professores e pedagogos. É também recomendada para os professores de as modalidades de ensino servindo de apoio para releituras de proposições de pesquisa e atuação na formação continuada de professores, enfocando o olhar para o envolvimento e a colaboração dos atores da prática cotidiana escolar, levando em consideração os pressupostos da prática e cadeias relacionais apresentadas.

\section{REFERÊNCIAS}

TARDIF, M.; LESSARD, C.O trabalho docente: elementos para uma teoria da docência como profissão de interações humanas. Petrópolis, RJ: Vozes, 2005.

TARDIF, M. Saberes docentes e formação profissional. Petrópolis, RJ: Vozes, 2002.

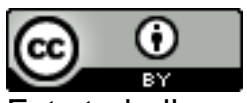

Este trabalho está licenciado com uma Licença Creative Commons - Atribuição 4.0 Internacional 